\title{
Chapter 12 \\ Molecular and Biochemical Characterization of the SARS-CoV Accessory Proteins ORF8a, ORF8b and ORF8ab
}

\author{
Choong-Tat Keng and Yee-Joo Tan
}

\begin{abstract}
A novel coronavirus was identified as the aetiological agent for the global outbreak of severe acute respiratory syndrome (SARS) at the beginning of the twenty-first century. The SARS coronavirus genome encodes for proteins that are common to all members of the coronavirus, i.e. replicase polyproteins (ppla and pplb) and structural proteins (spike, membrane, nucleocapsid and envelope), as well as eight accessory proteins. The accessory proteins have been designated as open reading frames (ORF) 3a, 3b, 6, 7a, 7b, 8a, 8b and 9b, and they do not show significant homology to viral proteins of other known coronaviruses. Epidemiological studies have revealed that the part of the viral genome that encodes for ORF8a and ORF8b showed major variations and the animal isolates contain an additional 29-nucleotide sequence which is absent in most of the human isolates. As a result, ORF8a and ORF8b in the human isolates become one ORF, termed ORF8ab. In this chapter, we will discuss the genetic variation in the ORF8 region, expression of ORF8a, ORF8b and ORF8ab during infection, cellular localization and posttranslational modification of ORF8a, ORF8b and ORF8ab, participation of ORF8a, ORF8b and ORF8ab in viral-viral interactions, their effects on other viral proteins and impact on viral replication and/or pathogenesis.
\end{abstract}

\subsection{Introduction}

A novel coronavirus was identified as the aetiological agent for the severe acute respiratory syndrome (SARS) epidemic in 2003 (Drosten et al. 2003; Poon et al. 2004). In addition to the replicase polyproteins (pp1a and pp1ab) and structural proteins (spike $(\mathrm{S})$, membrane $(\mathrm{M})$, nucleocapsid $(\mathrm{N})$ and envelope $(\mathrm{E})$ ) which are

\footnotetext{
Y.-J. Tan $(\bowtie)$

Collaborative Anti-Viral Research Group, Institute of Molecular and Cell Biology, 61 Biopolis Drive, Proteos, Singapore 138673

e-mail: mcbtanyj@imcb.a-star.edu.sg
} 
common to all members of the coronavirus genus, the SARS coronavirus (SARS$\mathrm{CoV}$ ) genome also encodes eight accessory proteins, i.e. open reading frames (ORFs) 3a, 3b, 6, 7a, 7b, 8a, 8b and 9b, varying in length from 39 to 274 amino acids (Marra et al. 2003; Snijder et al. 2003). While the SARS-CoV replicase gene products and structural proteins share some degree of sequence homology with those of other coronaviruses, the accessory proteins do not show significant homology to viral proteins of known coronaviruses. Indeed, many laboratories have performed molecular and biochemical characterization of these accessory proteins (Tan et al. 2006; Narayanan et al. 2008), as a better understanding of these unique SARS-CoV proteins may offer clues as to why the SARS-CoV causes such a severe and rapid attack in humans while other coronaviruses that infect humans seem to be more forgiving.

Interestingly, epidemiological studies have revealed that the part of the viral genome that encodes for two of these accessory proteins, ORF8a and ORF8b, shows major variations. In one of these studies, Guan and coworkers analysed SARS-CoV isolates obtained from animals in a live-market in Guangdong and found that all the animal isolates contained a 29-nucleotide (nt) sequence which is absent in most of the human isolates (Guan et al. 2003) (Fig. 12.1a). As a result of this, the ORF8a and ORF8b (also termed as ORF10 and ORF11 respectively) in the

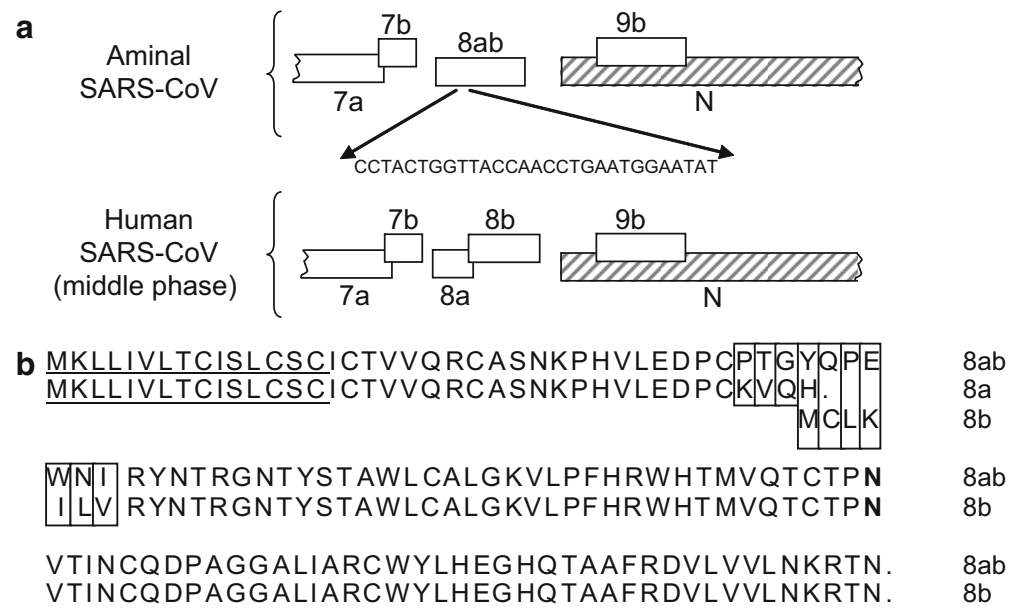

Fig. 12.1 (a) Schematic diagram showing the genetic difference in the ORF8 region of the SARS$\mathrm{CoV}$ isolated from animals and humans infected during the middle phase of the SARS epidemic in 2003. The animal isolates have an extra 29-nucleotide insertion such that the subgenomic RNA8 encodes for a single protein, termed ORF8ab, while that of the human isolates (from the middle phase) encodes two proteins, ORF8a and ORF8b. Human isolates from early phase of the epidemic also have the 29-nucleotide insertion found in the animal SARS-CoV. (b) Alignment of the protein sequences of ORF8a, ORF8b and ORF8ab. Mismatches between ORF8a and ORF8ab or ORF8b and ORF8ab are boxed. The predicted signal peptides in ORF8a and ORF8ab are underlined and the predicted $\mathrm{N}$-glycosylation sites in these proteins are showed in bold. The ORF8ab is reconstructed from a human isolate from the middle phase (SIN2774) by insertion of the 29-nucletoides found in a human isolate from the early phase (GZ02). Dot represents the stop codon 
human isolates become one ORF, termed as ORF8ab. ORF8ab encodes a protein of 122 amino acids, whose $\mathrm{N}$ terminus is identical to ORF8a and $\mathrm{C}$ terminus is identical to ORF8b (Fig. 12.1b). For simplification, we shall term the isolates obtained from wet-market animals as animal SARS-CoVs and those without the additional 29-nt in the ORF8 region as human SARS-CoVs.

In this chapter, we summarize present knowledge of the two accessory proteins, ORF8a and ORF8b, encoded by subgenomic mRNA8 of the human SARS-CoV, as well as their counterpart in animal SARS-CoV, ORF8ab. Although the mutations in the ORF8 region do not appear to have any adverse effect on the survival of the virus, it is conceivable that the ORF8a, ORF8b and ORF8ab proteins have different stabilities and/or functions, and hence would contribute differently to viral replication and/or pathogenesis in vivo. In order to understand how the variations in the ORF8 region of the viral genome may influence SARS-CoV infection, we will discuss the genetic variations in the ORF8 region, expression of ORF8a, ORF8b and ORF8ab during infection, cellular localization and posttranslational modification of ORF8a, ORF8b and ORF8ab, participation of ORF8a, ORF8b and ORF8ab in viral-viral interactions, their effects on other viral proteins and impact on viral replication and/or pathogenesis.

\subsection{Genetic Variations in the ORF8 Region}

When a virus is first introduced into the human population from an animal source, it has to undergo evolution in order to optimize the entry, replication and budding processes as well as to evade immune responses. Thus, genetic and epidemiological studies yield valuable insights on how viruses cross the species barrier and evolve to cause disease in humans. Indeed, such studies conducted on the SARS-CoV have revealed that this virus crossed the animal-human barrier recently (Donnelly et al. 2004; Guan et al. 2003; Lau et al. 2005; Song et al. 2005). Large genetic variations have also been found in the ORF8 region. Interestingly, the animal strains of SARS$\mathrm{CoV}$, isolated from a raccoon dog and palm civets in markets/restaurants and from wild bats, contain an extra 29-nt in the ORF8 region (Guan et al. 2003; Lau et al. 2005).

Another extensive study of 63 SARS-CoV isolates obtained from the SARS epidemic in China also showed that there are major variations in this region of the viral genome (The Chinese SARS Molecular Epidemiology Consortium 2004). In this study, the course of the epidemic was divided into the early, middle and late phases with the early phase defined as the period of first emergence of SARS in Guangdong Province, China, 2002. The middle phase referred to all events up to the first cluster of SARS cases in the Metropole hotel in Hong Kong and the late phase referred to all cases following this cluster. Interestingly, the clustering of patients with different patterns of variation in ORF8 region was correlated with the different phases of the epidemic. The 29-nt sequence is not found in all the human strains that were isolated in the middle phase of the epidemic but is present in most of the human isolates from the early phase. Indeed, human infection in the early phase 
probably represents the first breach of the animal-human barrier as these isolates share the closest phylogenetic relationship with the animal isolates. These findings were subsequently verified by researchers who studied the SARS-CoVs isolated in different countries (Lan et al. 2005; Qin et al. 2003; Wang et al. 2005).

After the WHO's declaration of the end of the SARS epidemic, there were four confirmed SARS patients in Guangzhou, China, in late 2003 to early 2004 (Liang et al. 2004; Song et al. 2005). These patients did not have any contact history with previously documented SARS cases. Sequence analysis of viruses isolated from these patients showed that they were not derived from the preceding epidemic in 2003 but rather suggested that these cases represented new zoonotic transmissions (Song et al. 2005). Like the animal isolates, these viruses also contain the additional 29-nt in the ORF8 region.

These findings clearly indicate that the deletion of the extra 29-nt in ORF8 is not necessary for animal-human transmission, as human SARS-CoVs isolated from early phase still contain these nucleotides. However, during infection in humans, the deletion of the 29-nt seems to occur quickly. Besides this deletion, other types of deletion close to or within the ORF8 region have also been reported. For example, the viruses isolated from some patients in Hong Kong were found to contain a deletion of 386-nt that flanks the 29-nt site (The Chinese SARS Molecular Epidemiology Consortium 2004; Chiu et al. 2005). This causes the ORF7b to become smaller and eliminates both ORF8a and ORF8b. In addition, a frame-shift mutation in the ORF $8 a$ gene was also reported for two isolates that had been passaged in Vero E6 or FRhK4 cells (Poon et al. 2005). This mutation was not found in the original clinical samples, suggesting that this mutation was acquired as a result of cell culture adaptation. Interestingly, deletion mutations that lead to premature stop of the ORF8a protein have also been found in three other human isolates (Lan et al. 2005).

Analysis of the variation in the sequences of S protein show that SARS-CoV has rapidly evolved during the SARS epidemic and that the virus was undergoing adaptation in the human host (Song et al. 2005; The Chinese SARS Molecular Epidemiology Consortium 2004). While it is clear that the $S$ gene was undergoing positive selection (Holmes 2005; Zhao 2007), whether the genetic variation in the ORF8 region is a result of viral adaptation or genomic instability remains to be determined.

\subsection{Expression of ORF8a, ORF8b and ORF8ab During Infection}

\subsubsection{Expression During Infection In Vivo}

During viral infection, the host's immune system is stimulated to defend it against the invading virus. Subsequently, antibody responses against viral proteins can be detected in the sera of infected patients. Serological assays have been used to 
determine if SARS-CoV infected patients have antibodies against the SARS-CoV accessory proteins (Tan et al. 2005). In one study, two out of 37 patients were found to have anti-ORF8a antibodies suggesting that ORF8a was expressed during infection in vivo (Chen et al. 2007). Since only 5.4\% of the patients had anti-ORF8a antibodies, this suggests that ORF8a may be expressed at low levels or that it is not highly immunogenic. While this study used full-length ORF8a expressed in bacteria as well as mammalian cells to determine the presence of anti-ORF8a antibodies, another study used overlapping peptides of ORF8a instead (Guo et al. 2004). Here, they examined four pairs of acute and convalescent sera and found that two of the convalescent sera contained IgA antibodies against ORF8a while none of the acute sera had such antibodies. In the same study, no anti-ORF8b antibody was found.

Thus, these studies show that ORF8a can be expressed during infection in vivo but there is no evidence for the expression of ORF8b. Due to the high similarity in the amino acid sequences of ORF8a and ORF8ab, it is difficult to distinguish between the antibodies against ORF8a and ORF8ab in these patients. As no sequencing was performed for the samples from these patients, it is also not known if the 29-nt insertion is present in the viral genomes.

\subsubsection{Expression During Infection In Vitro}

Since SARS-CoV grows well in cell culture, different groups also generated ORF8a and ORF8b specific antibodies in order to determine their expression during infection in vitro. In our laboratory, we have been successful in detecting the expression of ORF8a and ORF8b in SARS-CoV infected Vero E6 cells that were infected with an isolate from a SARS patient in Singapore (SARS CoV 2003VA2774) (Keng et al. 2006). ORF8a and ORF8b were found to be localized in the cytoplasm of the infected cells at a late time point of infection. Similar results were obtained when the experiment was repeated with the HKU39849 Hong Kong isolate (unpublished data). However, another laboratory could not detect ORF8b in SARS-CoV (strain 5688) infected Vero E6 cells, indicating that ORF8b is not, or only very inefficiently, expressed during infection (Oostra et al. 2007). The difference between these two studies may be due to the specificity and affinity of the antibodies used or the different time-point of infection studied. Thus far, the expression of ORF8ab during infection in vitro has not been documented.

ORF8 $\mathrm{a}$ and ORF8b are encoded by the bicistronic subgenomic RNA8 produced in SARS-CoV infected cells (Marra et al. 2003; Snijder et al. 2003). Since its translation initiation codon is not the first AUG in the subgenomic RNA8, ORF8b is likely to be expressed via an internal ribosomal entry mechanism or by a leaky ribosomal scanning mode of translation, as have been described for viral proteins encoded by other bicistonic or tricistronic coronaviral mRNAs (Liu and Inglis 1992; Senanayake and Brian 1997; Thiel and Siddell 1994). Thus, the recombinant vaccinia virus bacteriophage T7 RNA polymerase expression system was further used to generate mRNA that mimics the subgenomic RNA8 generated in infected 
cells (Oostra et al. 2007). Again, ORF8b could not be expressed using this system, indicating that the human SARS-CoV may not contain an internal ribosomal entry site for the expression of ORF8b. Similar results were independently reported by another laboratory (Le et al. 2007).

\subsection{Cellular Localization and Posttranslational Modification of ORF8a, ORF8b and ORF8ab}

\subsubsection{Cellular Localization}

Immunofluorescence experiments performed on Vero E6 transfected with a cDNA construct containing the ORF8a gene show that untagged ORF8a is localized in the mitochondria (Chen et al. 2007). In contrast, ORF8a tagged at the $C$ terminus with the enhanced green fluorescent protein (EGFP) was reported to colocalize with calreticulin, an endoplasmic reticulum (ER) marker (Oostra et al. 2007). In the latter study, ORF8ab-EGFP was also found in the ER while ORF8b-EGFP was distributed throughout the entire cell.

In a separate study, the cellular localization of untagged ORF8a, ORF8b and ORF8ab, also expressed using cDNA constructs, were compared by using specific antibodies against ORF8a and ORF8b (Keng et al. 2006). ORF8a and ORF8b were found in punctuate vesicle-like structures throughout the cytoplasm but no cellular marker was used to determine the nature of these structures. On the other hand, ORF8ab was found to be diffused in the cytoplasm. Hence, there appear to be significant differences in the conformations of ORF8a and ORF8ab, although 35 out of 39 amino acids of ORF8a are present in ORF8ab (Fig. 12.1b). Similarly, 77 out of 84 amino acids of ORF8b are present in ORF8ab, but the cellular localization of ORF8b is distinct from ORF8ab. The vesicular staining for the ORF8b protein was also observed when the protein is tagged at either the $\mathrm{N}$ or $\mathrm{C}$ terminus with the FLAG tag (von Brunn et al. 2007).

The discrepancies between the different studies may be due to the use of different antibodies. In addition, some laboratories expressed the native proteins while other expressed them fused with different tags (for detection purposes). Given that ORF8a, ORF8b and ORF8ab are rather small proteins, it is probable that fusion with some tags can affect their cellular localization. As all these studies were performed by over-expressing the viral proteins, the exact cellular localization of these proteins in the SARS-CoV infected cells still needs to be examined carefully.

\subsubsection{Glycosylation}

ORF8ab is predicted to contain a cleavable signal sequence which directs the precursor to the ER and mediates its translocation into the lumen (Oostra et al. 
2007). Indeed, when ORF8ab was expressed using the vaccinia virus T7 expression system, the precursor was observed to be cleaved efficiently to yield a cleaved protein that became $N$-glycosylated, assembled into disulfide-linked homomultimeric complexes, and remained stably in the ER. This was confirmed by an independent study which also used site-directed mutagenesis to show that ORF8ab is $N$-glycosylated on the Asn81 residue (Le et al. 2007).

ORF8a contains the same signal peptide as ORF8ab but this signal cannot function due to the shortness of the ORF8a polypeptide (Oostra et al. 2007). However, if ORF8a is tagged at its $\mathrm{C}$ terminus with EGFP, then the glycosylation of the fusion protein can be observed. Similar experiments performed on ORF8b showed that it is not glycosylated.

\subsubsection{Ubiquitination}

Another possible explanation for the difficulties encountered by some laboratories in detecting ORF8b in SARS-CoV infected cells (see Sect. 12.3.2) is that the protein may be unstable. In order to determine if ORF8b and ORF8ab are posttranslationally modified by ubiquitination, co-immunoprecipitation experiments were performed after the proteins and myc-tagged ubiquitin were over-expressed in HeLa cells (Le et al. 2007). The results showed that ORF8b and ORF8ab can interact with monoubiquitin and polyubiquitin and this was also confirmed by using ORF8b and ORF8ab expressed as glutathione $S$-transferase-fusion proteins in bacteria.

Although both ORF8b and ORF8ab can become ubiquitinated, ORF8b, but not ORF8ab, seems to undergo rapid degradation when expressed using an infectious clone system derived from the coronavirus infectious bronchitis virus (IBV) (Le et al. 2007). The degradation of ORF8b can be blocked with proteasome inhibitors, suggesting that it is degraded via the proteasome pathway. Interestingly, when the glycosylation of ORF8ab is abolished through the substitution of Asn81 with Asp (see Sect. 12.4.2), it also becomes more susceptible to degradation. Thus, it appears that glycosylation may assist in the folding of ORF8ab, and the lack of glycosylation of ORF8b results in a highly unstable protein.

\subsection{Participation of ORF8a, ORF8b and ORF8ab in Viral-Viral Interactions and Their Effects on Other SARS-CoV Proteins}

\subsubsection{Interaction of ORF8a, ORF8b and ORF8ab with Other Viral Proteins}

Co-immunoprecipitation experiments have been performed to determine if ORF8a, ORF8b and ORF8ab can interact with the SARS-CoV structural proteins, S, M, E 
Table 12.1 The abilities of ORF8a, ORF8b and ORF8ab to interact with other viral proteins were determined by yeast-two-hybrid and co-immunoprecipitation assays

\begin{tabular}{llll}
\hline Interacting partners of: & ORF8a & ORF8b & ORF8ab \\
\hline nsp3N & $\mathrm{No}^{\mathrm{a}}$ & $\mathrm{Yes}^{\mathrm{a}}$ & N.D. \\
nsp8 & $\mathrm{Yes}^{\mathrm{a}, \mathrm{b}}$ & $\mathrm{Yes}^{\mathrm{a}, \mathrm{b}}$ & N.D. \\
nsp15 & $\mathrm{Yes}^{\mathrm{a}}$ & $\mathrm{No}^{\mathrm{a}}$ & $\mathrm{N} . D$. \\
S & $\mathrm{No}^{\mathrm{a}} / \mathrm{yes}^{\mathrm{c}}$ & $\mathrm{Yes}^{\mathrm{a}} / \mathrm{no}^{\mathrm{c}}$ & $\mathrm{Yes}^{\mathrm{c}}$ \\
$\mathrm{E}$ & $\mathrm{No}^{\mathrm{a} / \mathrm{yes}^{\mathrm{c}}}$ & $\mathrm{No}^{\mathrm{a}} / \mathrm{yes}^{\mathrm{c}}$ & $\mathrm{No}^{\mathrm{c}}$ \\
$\mathrm{M}$ & $\mathrm{No}^{\mathrm{a}, \mathrm{c}}$ & $\mathrm{No}^{\mathrm{a}} / \mathrm{yes}^{\mathrm{c}}$ & $\mathrm{Yes}^{\mathrm{c}}$ \\
ORF3a & $\mathrm{No}^{\mathrm{a}, \mathrm{c}}$ & $\mathrm{No}^{\mathrm{a}} / \mathrm{yes}^{\mathrm{c}}$ & $\mathrm{Yes}^{\mathrm{c}}$ \\
ORF7a & $\mathrm{No}^{\mathrm{a}, \mathrm{c}}$ & $\mathrm{No}^{\mathrm{a}} / \mathrm{yes}^{\mathrm{c}}$ & $\mathrm{Yes}^{\mathrm{c}}$ \\
ORF7b & $\mathrm{No}^{\mathrm{a}}$ & $\mathrm{Yes}^{\mathrm{a}}$ & $\mathrm{N} . D$. \\
ORF8a & $\mathrm{No}^{\mathrm{a}}$ & $\mathrm{Yes}^{\mathrm{a}}$ & N.D. \\
ORF8b & $\mathrm{Yes}^{\mathrm{a}}$ & $\mathrm{No}^{\mathrm{a}}$ & N.D. \\
ORF9b & $\mathrm{Yes}^{\mathrm{a}}$ & $\mathrm{Yes}^{\mathrm{a}}$ & N.D. \\
ORF14 & $\mathrm{No}^{\mathrm{a}}$ & $\mathrm{Yes}^{\mathrm{a}}$ & N.D. \\
\hline
\end{tabular}

${ }^{\mathrm{a}}$ Results taken from yeast-two-hybrid assay in von Brunn et al. (2007)

${ }^{\mathrm{b}}$ Results taken from co-immunoprecipitation assay in von Brunn et al. (2007)

${ }^{c}$ Results taken from co-immunoprecipitation assay in Keng et al. (2006)

N.D.:not determined

and $\mathrm{N}$, as well as two SARS-CoV accessory proteins, ORF3a and ORF7a (Keng et al. 2006). These results show that the binding profiles of ORF8a, ORF8b and ORF8ab are clearly distinct (Table 12.1), suggesting that the conformations of the ORF8a and ORF8b may be quite different from ORF8ab. Another group also performed a comprehensive analysis of intraviral protein-protein interactions of the SARS-CoV (von Brunn et al. 2007). The results from the yeast-two-hybrid system show that ORF8a and ORF8b are involved in numerous interactions with other viral proteins (Table 12.1). ORF8ab was not examined in this study. However, only the interactions of nsp8 with ORF8a and ORF8b were validated by co-immunoprecipitation experiments. There are some differences between these two studies (Table 12.1) but this is not surprising since protein-protein interactions observed in yeast are frequently not replicated in mammalian cells.

Although these viral-viral protein interactions need to be verified in infected cells, the findings of these studies suggest that ORF8a, ORF8b and ORF8ab may modulate the activities of other viral proteins by interacting with them. It is also interesting to note that ORF8a and ORF8b can interact with each other (von Brunn et al. 2007), but further studies are required to determine if this complex has the same function as ORF8ab.

\subsubsection{Downregulation of the $\mathrm{E}$ Protein by $\mathrm{ORF} 8 \mathrm{~b}$}

The expression of ORF8b was observed to downregulate the expression of $\mathrm{E}$ but the expression of $\mathrm{E}$ was not affected by either ORF8a or ORF8ab (Keng et al. 2006). 
Northern blot analysis showed that the mRNA level of E was not decreased in the presence of ORF8b, suggesting that the effect of ORF8b on the expression of the E protein is likely to be posttranslational. This finding was further confirmed by immunofluorescence studies which showed that the expressions of ORF8b and E in SARS-CoV infected cells were mutually exclusive (Keng et al. 2006). The effect of ORF8b on E can be blocked by proteasome inhibitors, suggesting that it involves the proteasome pathway (Le et al. 2007).

Although the coexpression of SARS-CoV E and M is sufficient for the assembly of viral-like particles in the baculovirus system (Ho et al. 2004; Mortola and Roy 2004), it was demonstrated by reverse genetic techniques that $\mathrm{E}$ is not essential for the replication of SARS-CoV in Vero E6, HuH-7 and CaCo-2 cells (DeDiego et al. 2007). However, the recombinant SARS-CoV lacking the $E$ gene (rSARS-CoVDeltaE) grew to lower titers than the recombinant wild-type virus, indicating that the $\mathrm{E}$ protein has an effect on virus growth. In addition, the rSARS-CoV-DeltaE virus was found to be attenuated in both hamsters and transgenic mice expressing the SARS-CoV receptor, human angiotensin converting enzyme-2 (hACE-2) (DeDiego et al. 2007, 2008), indicating that $\mathrm{E}$ is an important virulence factor. Based on this, it is attempting to speculate that the downregulation of $\mathrm{E}$ by ORF8b may have an effect on the virulence of SARS-CoV. However, this effect is likely to be only modulative as only a fraction of the infected cells expresses detectable levels of ORF8b (Keng et al. 2006). In order for ORF8b to be expressed via an internal ribosomal entry mechanism or by a leaky ribosomal scanning mode of translation (see Sect. 12.3.2), activation of certain host translational machineries may be necessary (Komar and Hatzoglou 2005; Stoneley and Willis 2004). Such activation may happen only in the fraction of the cells that is in a certain phase of the cell cycle or subjected to certain stimuli. This is probably why ORF8b can only be detected in a fraction of the SARS-CoV infected cells (Keng et al. 2006). Further experiments are needed to address this possibility and determine the temporal expression of ORF8b during the viral replication cycle. In addition, it was reported that over-expression of SARS-CoV E can induce apoptosis in T-cells (Yang et al. 2005), and thus the downregulation of E by ORF8b may also have an impact on viral pathogenesis.

\subsection{Impact of ORF8a, ORF8b and ORF8ab on Viral Replication and/or Pathogenesis}

\subsubsection{Contribution to Viral Replication}

It has been demonstrated that palm civets are equally susceptible to the human SARS-CoV isolate BJ01 from the middle phase (containing ORF8a and ORF8b) and the isolate GZ01 from the early phase (containing ORF8ab) (Wu et al. 2005). Although infection of the animals with BJ01 seems to result in higher average body 
temperature and stronger antibody responses, further experiments are required to confirm these observations. Using reverse genetic methods, Yount and coworkers created an Urbani strain with the 29-nt insertion so that the ORF8 of this human SARS-CoV became like the animal SARS-CoV (Yount et al. 2005). Consistent with Wu et al. 2005, their results show that this mutant virus replicates as well as the wild-type virus in mice, suggesting the 29-nt insertion does not enhance the replication of SARS-CoV in young mice, which cleared both viruses by day 7 postinfection.

These results suggest that ORF8a, ORF8b and ORF8ab are not essential for viral replication or pathogenesis in the mice and palm civet models. However, Chen and coworkers demonstrated that the over-expression of ORF8a can enhance viral replication in HuH-7 cells (Chen et al. 2007). When HuH-7 cell lines stably expressing ORF8a were infected with SARS-CoV, higher viral loads and greater cytopathic effects were observed when compared to the original $\mathrm{HuH}-7$ cells. In order to resolve the discrepancies between these observations, it is important to determine how much higher is the level of ORF8a in these stable cell lines compared to that expressed during SARS-CoV infection. In addition, it will be interesting to investigate if the differences are due to the types of cells used.

\subsubsection{Abilities to Modulate Cellular Events}

Both apoptosis and necrosis have been observed in various infected tissues obtained during autopsy studies on SARS casualties (Chau et al. 2004; Chong et al. 2004; Ding et al. 2003; Lang et al. 2003; Wei et al. 2007), indicating the occurrence of cell death during SARS infection in vivo. In addition, one of the most common abnormalities in SARS-CoV infected patients is lymphopenia (Peiris et al. 2003; Chng et al. 2005; Chen et al. 2006), which could be caused by the depletion of T lymphocytes by apoptosis. In one study, extensive apoptosis was observed in the hepatocytes of three SARS patients who had liver impairment, suggesting that liver damage in these patients may be mediated by apoptosis (Chau et al. 2004). Apoptosis was also observed in thyroid glands obtained from five fatal SARS cases (Wei et al. 2007).

The occurrence of apoptosis during SARS-CoV infection in vitro has also been studied by various groups (Mizutani et al. 2004; Tan et al. 2004; Yan et al. 2004; Ren et al. 2005; Bordi et al. 2006). The induction of apoptosis was dependent on viral replication and could be inhibited by caspase inhibitors or the over-expression of the prosurvival protein, Bcl-2 (Ren et al. 2005; Bordi et al. 2006). Furthermore, the over-expression of some of the SARS-CoV proteins can induce apoptosis and/or necrosis (Tan et al. 2007). Five of the accessory proteins, ORF3a, ORF3b, ORF6, ORF7a and ORF8a, have also been shown to induce apoptosis when they were over-expressed (Law et al. 2005; Tan et al. 2004; Yuan et al. 2005; Khan et al. 2006; Chen et al. 2007; Ye et al. 2008). In addition, ORF8a was found to be localized in 
the mitochondria (Chen et al. 2007). As a result, there is a high level of reactive oxygen species production, suggesting that the over-expression of ORF8a causes mitochondrial dysfunction, which results in apoptosis.

The over-expression of ORF8b has been shown to induce DNA synthesis, suggesting that it may have the ability to increase cell proliferation (Law et al. 2006). Another SARS-CoV accessory protein, ORF6, also has the same property (Geng et al. 2005). Coexpression of ORF8b and ORF6 did not yield any synergistic effects, suggesting that they may function independently (Law et al. 2006). However, the abilities of these proteins to modulate DNA synthesis have yet to be examined in the context of SARS-CoV infection.

\subsection{Conclusion}

Since the identification of the SARS-CoV in the year 2003, extensive research on the SARS-CoV has yielded significant understanding of this newly emerged virus. Interestingly, the SARS-CoV isolated from humans infected during the peak of epidemic, encodes two accessory proteins termed as ORF8a and ORF8b while the SARS-CoV isolated from animals contains an extra 29-nt in this region such that these proteins are fused to become a single protein, ORF8ab. As described above, the accessory proteins ORF8a and ORF8b are expressed during infection in vitro, but replacing them with ORF8ab does not affect SARS-CoV replication in cell culture or small animal models. However, it is still not known if these proteins contribute to viral replication and/or pathogenesis in the natural host. Significant differences in the molecular and biochemical characteristics of ORF8a, ORF8b and ORF8ab have been observed but the impact on the function of these proteins remains unclear. Another unanswered question is why large genetic variations have occurred most frequently in this particular region of the viral genome.

\section{References}

Bordi L, Castilletti C, Falasca L, Ciccosanti F, Calcaterra S, Rozera G, Di Caro A, Zaniratti S, Rinaldi A, Ippolito G, Piacentini M, Capobianchi MR (2006) Bcl-2 inhibits the caspasedependent apoptosis induced by SARS-CoV without affecting virus replication kinetics. Arch Virol 151(2):369-377

Chau TN, Lee KC, Yao H, Tsang TY, Chow TC, Yeung YC, Choi KW, Tso YK, Lau T, Lai ST, Lai CL (2004) SARS-associated viral hepatitis caused by a novel coronavirus: report of three cases. Hepatology 39(2):302-310

Chen RF, Chang JC, Yeh WT, Lee CH, Liu JW, Eng HL, Yang KD (2006) Role of vascular cell adhesion molecules and leukocyte apoptosis in the lymphopenia and thrombocytopenia of patients with severe acute respiratory syndrome (SARS). Microbes Infect 8(1):122-127

Chen CY, Ping YH, Lee HC, Chen KH, Lee YM, Chan YJ, Lien TC, Jap TS, Lin CH, Kao LS, Chen YM (2007) Open reading frame 8a of the human severe acute respiratory syndrome 
coronavirus not only promotes viral replication but also induces apoptosis. J Infect Dis 196 (3):405-415

Chiu RW, Chim SS, Tong YK, Fung KS, Chan PK, Zhao GP, Lo YM (2005) Tracing SARScoronavirus variant with large genomic deletion. Emerg Infect Dis 11(1):168-170

Chng WJ, Lai HC, Earnest A, Kuperan P (2005) Haematological parameters in severe acute respiratory syndrome. Clin Lab Haematol 27(1):15-20

Chong PY, Chui P, Ling AE, Franks TJ, Tai DY, Leo YS, Kaw GJ, Wansaicheong G, Chan KP, Ean Oon LL, Teo ES, Tan KB, Nakajima N, Sata T, Travis WD (2004) Analysis of deaths during the severe acute respiratory syndrome (SARS) epidemic in Singapore: challenges in determining a SARS diagnosis. Arch Pathol Lab Med 128(2):195-204

DeDiego ML, Alvarez E, Almazan F, Rejas MT, Lamirande E, Roberts A, Shieh WJ, Zaki SR, Subbarao K, Enjuanes L (2007) A severe acute respiratory syndrome coronavirus that lacks the E gene is attenuated in vitro and in vivo. J Virol 81(4):1701-1713

Dediego ML, Pewe L, Alvarez E, Rejas MT, Perlman S, Enjuanes L (2008) Pathogenicity of severe acute respiratory coronavirus deletion mutants in hACE-2 transgenic mice. Virology 376(2):379-389

Ding Y, Wang H, Shen H, Li Z, Geng J, Han H, Cai J, Li X, Kang W, Weng D, Lu Y, Wu D, He L, Yao K (2003) The clinical pathology of severe acute respiratory syndrome (SARS): a report from China. J Pathol 200(3):282-289

Donnelly CA, Fisher MC, Fraser C, Ghani AC, Riley S, Ferguson NM, Anderson RM (2004) Epidemiological and genetic analysis of severe acute respiratory syndrome. Lancet Infect Dis 4(11):672-683

Drosten C, Preiser W, Gunther S, Schmitz H, Doerr HW (2003) Severe acute respiratory syndrome: identification of the etiological agent. Trends Mol Med 9(8):325-327

Geng H, Liu YM, Chan WS, Lo AW, Au DM, Waye MM, Ho YY (2005) The putative protein 6 of the severe acute respiratory syndrome-associated coronavirus: expression and functional characterization. FEBS Lett 579(30):6763-6768

Guan Y, Zheng BJ, He YQ, Liu XL, Zhuang ZX, Cheung CL, Luo SW, Li PH, Zhang LJ, Guan YJ, Butt KM, Wong KL, Chan KW, Lim W, Shortridge KF, Yuen KY, Peiris JS, Poon LL (2003) Isolation and characterization of viruses related to the SARS coronavirus from animals in southern China. Science 302(5643):276-278

Guo JP, Petric M, Campbell W, McGeer PL (2004) SARS corona virus peptides recognized by antibodies in the sera of convalescent cases. Virology 324(2):251-256

Ho Y, Lin PH, Liu CY, Lee SP, Chao YC (2004) Assembly of human severe acute respiratory syndrome coronavirus-like particles. Biochem Biophys Res Commun 318(4):833-838

Holmes KV (2005) Structural biology. Adaptation of SARS coronavirus to humans. Science 309 (5742):1822-1823

Keng CT, Choi YW, Welkers MR, Chan DZ, Shen S, Gee Lim S, Hong W, Tan YJ (2006) The human severe acute respiratory syndrome coronavirus (SARS-CoV) $8 \mathrm{~b}$ protein is distinct from its counterpart in animal SARS-CoV and down-regulates the expression of the envelope protein in infected cells. Virology 354(1):132-142

Khan S, Fielding BC, Tan TH, Chou CF, Shen S, Lim SG, Hong W, Tan YJ (2006) Overexpression of severe acute respiratory syndrome coronavirus $3 \mathrm{~b}$ protein induces both apoptosis and necrosis in Vero E6 cells. Virus Res 122(1-2):20-27

Komar AA, Hatzoglou M (2005) Internal ribosome entry sites in cellular mRNAs: mystery of their existence. J Biol Chem 280(25):23425-23428

Lan YC, Liu HF, Shih YP, Yang JY, Chen HY, Chen YM (2005) Phylogenetic analysis and sequence comparisons of structural and non-structural SARS coronavirus proteins in Taiwan. Infect Genet Evol 5(3):261-269

Lang ZW, Zhang LJ, Zhang SJ, Meng X, Li JQ, Song CZ, Sun L, Zhou YS, Dwyer DE (2003) A clinicopathological study of three cases of severe acute respiratory syndrome (SARS). Pathology 35(6):526-531 
Lau SK, Woo PC, Li KS, Huang Y, Tsoi HW, Wong BH, Wong SS, Leung SY, Chan KH, Yuen KY (2005) Severe acute respiratory syndrome coronavirus-like virus in Chinese horseshoe bats. Proc Natl Acad Sci USA 102(39):14040-14045

Law PT, Wong CH, Au TC, Chuck CP, Kong SK, Chan PK, To KF, Lo AW, Chan JY, Suen YK, Chan HY, Fung KP, Waye MM, Sung JJ, Lo YM, Tsui SK (2005) The 3a protein of severe acute respiratory syndrome-associated coronavirus induces apoptosis in Vero E6 cells. J Gen Virol 86(Pt 7):1921-1930

Law PY, Liu YM, Geng H, Kwan KH, Waye MM, Ho YY (2006) Expression and functional characterization of the putative protein $8 \mathrm{~b}$ of the severe acute respiratory syndrome-associated coronavirus. FEBS Lett 580(15):3643-3648

Le TM, Wong HH, Tay FP, Fang S, Keng CT, Tan YJ, Liu DX (2007) Expression, posttranslational modification and biochemical characterization of proteins encoded by subgenomic mRNA8 of the severe acute respiratory syndrome coronavirus. FEBS J 274(16): 4211-4222

Liang G, Chen Q, Xu J, Liu Y, Lim W, Peiris JS, Anderson LJ, Ruan L, Li H, Kan B, Di B, Cheng P, Chan KH, Erdman DD, Gu S, Yan X, Liang W, Zhou D, Haynes L, Duan S, Zhang X, Zheng H, Gao Y, Tong S, Li D, Fang L, Qin P, Xu W (2004) Laboratory diagnosis of four recent sporadic cases of community-acquired SARS, Guangdong Province, China. Emerg Infect Dis 10(10):1774-1781

Liu DX, Inglis SC (1992) Internal entry of ribosomes on a tricistronic mRNA encoded by infectious bronchitis virus. J Virol 66(10):6143-6154

Marra MA, Jones SJ, Astell CR, Holt RA, Brooks-Wilson A, Butterfield YS, Khattra J, Asano JK, Barber SA, Chan SY, Cloutier A, Coughlin SM, Freeman D, Girn N, Griffith OL, Leach SR, Mayo M, McDonald H, Montgomery SB, Pandoh PK, Petrescu AS, Robertson AG, Schein JE, Siddiqui A, Smailus DE, Stott JM, Yang GS, Plummer F, Andonov A, Artsob H, Bastien N, Bernard K, Booth TF, Bowness D, Czub M, Drebot M, Fernando L, Flick R, Garbutt M, Gray M, Grolla A, Jones S, Feldmann H, Meyers A, Kabani A, Li Y, Normand S, Stroher U, Tipples GA, Tyler S, Vogrig R, Ward D, Watson B, Brunham RC, Krajden M, Petric M, Skowronski DM, Upton C, Roper RL (2003) The genome sequence of the SARS-associated coronavirus. Science 300(5624):1399-1404

Mizutani T, Fukushi S, Saijo M, Kurane I, Morikawa S (2004) Phosphorylation of p38 MAPK and its downstream targets in SARS coronavirus-infected cells. Biochem Biophys Res Commun 319(4):1228-1234

Mortola E, Roy P (2004) Efficient assembly and release of SARS coronavirus-like particles by a heterologous expression system. FEBS Lett 576(1-2):174-178

Narayanan K, Huang C, Makino S (2008) SARS coronavirus accessory proteins. Virus Res 133 (1):113-121

Oostra M, de Haan CA, Rottier PJ (2007) The 29-nucleotide deletion present in human but not in animal severe acute respiratory syndrome coronaviruses disrupts the functional expression of open reading frame 8. J Virol 81(24):13876-13888

Peiris JS, Yuen KY, Osterhaus AD, Stohr K (2003) The severe acute respiratory syndrome. N Engl J Med 349(25):2431-2441

Poon LL, Guan Y, Nicholls JM, Yuen KY, Peiris JS (2004) The aetiology, origins, and diagnosis of severe acute respiratory syndrome. Lancet Infect Dis 4(11):663-671

Poon LL, Leung CS, Chan KH, Yuen KY, Guan Y, Peiris JS (2005) Recurrent mutations associated with isolation and passage of SARS coronavirus in cells from non-human primates. J Med Virol 76(4):435-440

Qin E, He X, Tian W, Liu Y, Li W, Wen J, Wang J, Fan B, Wu Q, Chang G, Cao W, Xu Z, Yang R, Yu M, Li Y, Xu J, Si B, Hu Y, Peng W, Tang L, Jiang T, Shi J, Ji J, Zhang Y, Ye J, Wang C, Han Y, Zhou J, Deng Y, Li X, Hu J, Yan C, Zhang Q, Bao J, Li G, Chen W, Fang L, Li C, Lei M, Li D, Tong W, Tian X, Zhang B, Zhang H, Zhao H, Zhang X, Li S, Cheng X, Liu B, Zeng C, Tan X, Liu S, Dong W, Wong GK, Yu J, Zhu Q, Yang H (2003) A genome sequence of novel SARS-CoV isolates: the genotype, GD-Ins29, leads to a hypothesis of viral transmission in South China. Genomics Proteomics Bioinformatics 1(2):101-107 
Ren L, Yang R, Guo L, Qu J, Wang J, Hung T (2005) Apoptosis induced by the SARS-associated coronavirus in Vero cells is replication-dependent and involves caspase. DNA Cell Biol 24 (8):496-502

Senanayake SD, Brian DA (1997) Bovine coronavirus I protein synthesis follows ribosomal scanning on the bicistronic N mRNA. Virus Res 48(1):101-105

Snijder EJ, Bredenbeek PJ, Dobbe JC, Thiel V, Ziebuhr J, Poon LL, Guan Y, Rozanov M, Spaan WJ, Gorbalenya AE (2003) Unique and conserved features of genome and proteome of SARS-coronavirus, an early split-off from the coronavirus group 2 lineage. J Mol Biol 331 (5):991-1004

Song HD, Tu CC, Zhang GW, Wang SY, Zheng K, Lei LC, Chen QX, Gao YW, Zhou HQ, Xiang H, Zheng HJ, Chern SW, Cheng F, Pan CM, Xuan H, Chen SJ, Luo HM, Zhou DH, Liu YF, He JF, Qin PZ, Li LH, Ren YQ, Liang WJ, Yu YD, Anderson L, Wang M, Xu RH, Wu XW, Zheng HY, Chen JD, Liang G, Gao Y, Liao M, Fang L, Jiang LY, Li H, Chen F, Di B, He LJ, Lin JY, Tong S, Kong X, Du L, Hao P, Tang H, Bernini A, Yu XJ, Spiga O, Guo ZM, Pan HY, He WZ, Manuguerra JC, Fontanet A, Danchin A, Niccolai N, Li YX, Wu CI, Zhao GP (2005) Cross-host evolution of severe acute respiratory syndrome coronavirus in palm civet and human. Proc Natl Acad Sci USA 102(7):2430-2435

Stoneley M, Willis AE (2004) Cellular internal ribosome entry segments: structures, trans-acting factors and regulation of gene expression. Oncogene 23(18):3200-3207

Tan YJ, Fielding BC, Goh PY, Shen S, Tan TH, Lim SG, Hong W (2004) Overexpression of 7a, a protein specifically encoded by the severe acute respiratory syndrome coronavirus, induces apoptosis via a caspase-dependent pathway. J Virol 78(24):14043-14047

Tan YJ, Lim SG, Hong W (2005) Characterization of viral proteins encoded by the SARScoronavirus genome. Antiviral Res 65(2):69-78

Tan YJ, Lim SG, Hong W (2006) Understanding the accessory viral proteins unique to the severe acute respiratory syndrome (SARS) coronavirus. Antiviral Res 72(2):78-88

Tan YJ, Lim SG, Hong W (2007) Regulation of cell death during infection by the severe acute respiratory syndrome coronavirus and other coronaviruses. Cell Microbiol 9(11):2552-2561

The Chinese SARS Molecular Epidemiology Consortium (2004) Molecular evolution of the SARS coronavirus during the course of the SARS epidemic in China. Science 303 (5664):1666-1669

Thiel V, Siddell SG (1994) Internal ribosome entry in the coding region of murine hepatitis virus mRNA 5. J Gen Virol 75(Pt 11):3041-3046

von Brunn A, Teepe C, Simpson JC, Pepperkok R, Friedel CC, Zimmer R, Roberts R, Baric R, Haas J (2007) Analysis of intraviral protein-protein interactions of the SARS coronavirus ORFeome. PLoS ONE 2(5):e459

Wang ZG, Zheng ZH, Shang L, Li LJ, Cong LM, Feng MG, Luo Y, Cheng SY, Zhang YJ, Ru MG, Wang ZX, Bao QY (2005) Molecular evolution and multilocus sequence typing of 145 strains of SARS-CoV. FEBS Lett 579(22):4928-4936

Wei L, Sun S, Xu CH, Zhang J, Xu Y, Zhu H, Peh SC, Korteweg C, McNutt MA, Gu J (2007) Pathology of the thyroid in severe acute respiratory syndrome. Hum Pathol 38(1):95-102

Wu D, Tu C, Xin C, Xuan H, Meng Q, Liu Y, Yu Y, Guan Y, Jiang Y, Yin X, Crameri G, Wang M, Li C, Liu S, Liao M, Feng L, Xiang H, Sun J, Chen J, Sun Y, Gu S, Liu N, Fu D, Eaton BT, Wang LF, Kong X (2005) Civets are equally susceptible to experimental infection by two different severe acute respiratory syndrome coronavirus isolates. J Virol 79(4):2620-2625

Yan H, Xiao G, Zhang J, Hu Y, Yuan F, Cole DK, Zheng C, Gao GF (2004) SARS coronavirus induces apoptosis in Vero E6 cells. J Med Virol 73(3):323-331

Yang Y, Xiong Z, Zhang S, Yan Y, Nguyen J, Ng B, Lu H, Brendese J, Yang F, Wang H, Yang XF (2005) Bcl-xL inhibits T-cell apoptosis induced by expression of SARS coronavirus E protein in the absence of growth factors. Biochem J 392(Pt 1):135-143

Ye Z, Wong CK, Li P, Xie Y (2008) A SARS-CoV protein, ORF-6, induces Caspase-3 mediated, ER stress and JNK dependent apoptosis. Biochim Biophys Acta 1780(12):1383-1387 
Yount B, Roberts RS, Sims AC, Deming D, Frieman MB, Sparks J, Denison MR, Davis N, Baric RS (2005) Severe acute respiratory syndrome coronavirus group-specific open reading frames encode nonessential functions for replication in cell cultures and mice. J Virol 79 (23):14909-14922

Yuan X, Shan Y, Zhao Z, Chen J, Cong Y (2005) G0/G1 arrest and apoptosis induced by SARS-CoV 3 b protein in transfected cells. Virol J 2:66

Zhao GP (2007) SARS molecular epidemiology: a Chinese fairy tale of controlling an emerging zoonotic disease in the genomics era. Philos Trans R Soc Lond B Biol Sci 362(1482): $1063-1081$ 